\title{
Determinants of follow-up care associated with incident antidepressant use in older adults
}

Victoire Massamba ${ }^{1,4^{*}}$, Helen-Maria Vasiliadis ${ }^{2,3,4}$ and Michel Préville $2,3,4$

\begin{abstract}
Objectives: To determine the proportion of older adults receiving guideline concordant antidepressant therapy and to determine patient, prescriber and organizational factors associated with adequate antidepressant therapy.

Methods: The study included secondary analyses of data collected in the Étude sur la Santé des Aînés (ESA) Services study on older adults recruited while consulting in primary care clinics in one of the largest health regions of the province of Québec. Antidepressant users $(n=349)$ were identified from information collected from the Régie de I'Assurance Maladie du Québec (RAMQ) pharmaceutical database which holds information on all drugs dispensed to all residents covered under the public drug plan. Adequacy of antidepressant treatment was measured using three criteria: adequacy of daily dose; length of prescription ( $\geq 455$ days); and $\geq 3$ visits to the antidepressant-prescribing physician in the first 3 months after initiation of therapy. Multivariate logistic regression analyses were used to study antidepressant treatment adequacy as a function of individual, provider and healthcare system factors.
\end{abstract}

Results: Among the antidepressant users, $44 \%$ received an adequate antidepressant treatment filling all three criteria. None of the factors studied were associated with the probability of receiving adequate treatment filling all three criteria. Psychological distress was associated with having an adequate number of visits in the 3 months following initiation. Males and those living in a metropolitan and urban area were less likely to receive an adequate dose.

Conclusions: Future research should consider factors associated with perceived effectiveness and patient treatment preferences that may explain receipt of adequate antidepressant treatment in older adults.

Keywords: Adequacy, Antidepressants, Older adults, Primary care

\section{Background}

The literature in the United States has shown that less than $50 \%$ of depressed older adults receive antidepressant therapy $[1,2]$ and among those who do, studies have also reported that antidepressant prescribing patterns are inconsistent with treatment recommendations regarding dosage, duration and monitoring with follow-up visits [1].

Inadequate antidepressant treatment for depression undermines the effectiveness of treatment for the individual including an increased risk of recurrence

\footnotetext{
*Correspondence: Victoire.Massamba@USherbrooke.ca

${ }^{1}$ Clinical Sciences Program, Faculty of Medicine and Health Sciences,

Université de Sherbrooke, Sherbrooke, QC, Canada

Full list of author information is available at the end of the article
}

of depression [3, 4]. In fact, Hepner et al. showed that greater adherence to antidepressant practice guidelines was associated with clinical improvement of depressive symptoms [5]. Others have also shown that guidelineconcordant care for depression was associated with decreased years lived with disability [6].

Studies examining adequacy of antidepressant treatment, using quality indicators that include adequate dose, adequate duration and follow-up visits in older adult populations seen in general medical practice settings is limited [7]. Previous studies, in older adults and mixed-age populations, on the adequacy of the antidepressant therapy have underlined a number of associated factors. Many have shown individual predisposing factors such as age, sex, race, education level [8-11] as well as 
need factors such as perceived need for medication, comorbidity of depression and anxiety, and physical health status to be associated with adequate antidepressant therapy $[10,12,13]$. Healthcare system facilitating factors such as mental health specialty, physician use of depression treatment algorithms, health insurance coverage and number of follow-up visits to the prescribing physician have also been associated with receipt of adequate antidepressant therapy $[9,13,14]$.

Given the aging of the population, a higher prevalence of depression among primary care older patients is expected in the future. The adequacy and quality of antidepressant treatment in older adults following published guidelines [15] becomes an important issue in primary care and the efficiency of the health system. This study included secondary analysis of data from the ESA Services study. According to Andersen and Newman's model, which suggests that healthcare seeking behavior is influenced by predisposing, enabling and need factors [16], the objectives of this study were twofold. First, to determine the proportion of older adults receiving guideline concordant antidepressant therapy. Second, to determine patient, prescriber and organizational factors (Fig. 1) associated with adequate antidepressant therapy.

\section{Methods}

Data came from the Étude sur la Santé des Aînés (ESA) Services study, a cross-sectional survey conducted between 2011 and 2013 on older adults $(\mathrm{n}=1765)$ consulting in primary healthcare settings in one of the health regions of the province of Québec. The health and social services' agency taking part in our study is responsible for a population of 1,325,000 inhabitants. The study population, data collection procedures and recruitment strategies are described in more detail in previous publications $[17,18]$. The study was approved by the ethics committee of the University of Sherbrooke's Institute of Geriatrics. Briefly, respondents aged $\geq 65$ years old were recruited via participating GP clinics waiting rooms. Volunteers were invited to participate in a face-to-face interview at home. Respondents scoring below $22(n=46)$ on the Mini-Mental State Examination were excluded at the beginning of the interview [19]. Participants who were covered under the public drug plan were included in the present study. In Québec, all residents are covered for medical services and hospitalisations with the RAMQ, Québec's public health insurance plan. The RAMQ medical services files contain the date of medical acts, procedures and consultations, diagnoses, practice type of primary care clinics, physician specialty and gender. The analytic sample used in this study included respondents who were also covered under the public drug insurance plan and who accepted that their survey data be linked to their RAMQ medical file and who had filled an antidepressant prescription ( $\mathrm{n}=349)$ (Fig. 2). The RAMQ pharmaceutical database does not include the diagnosis

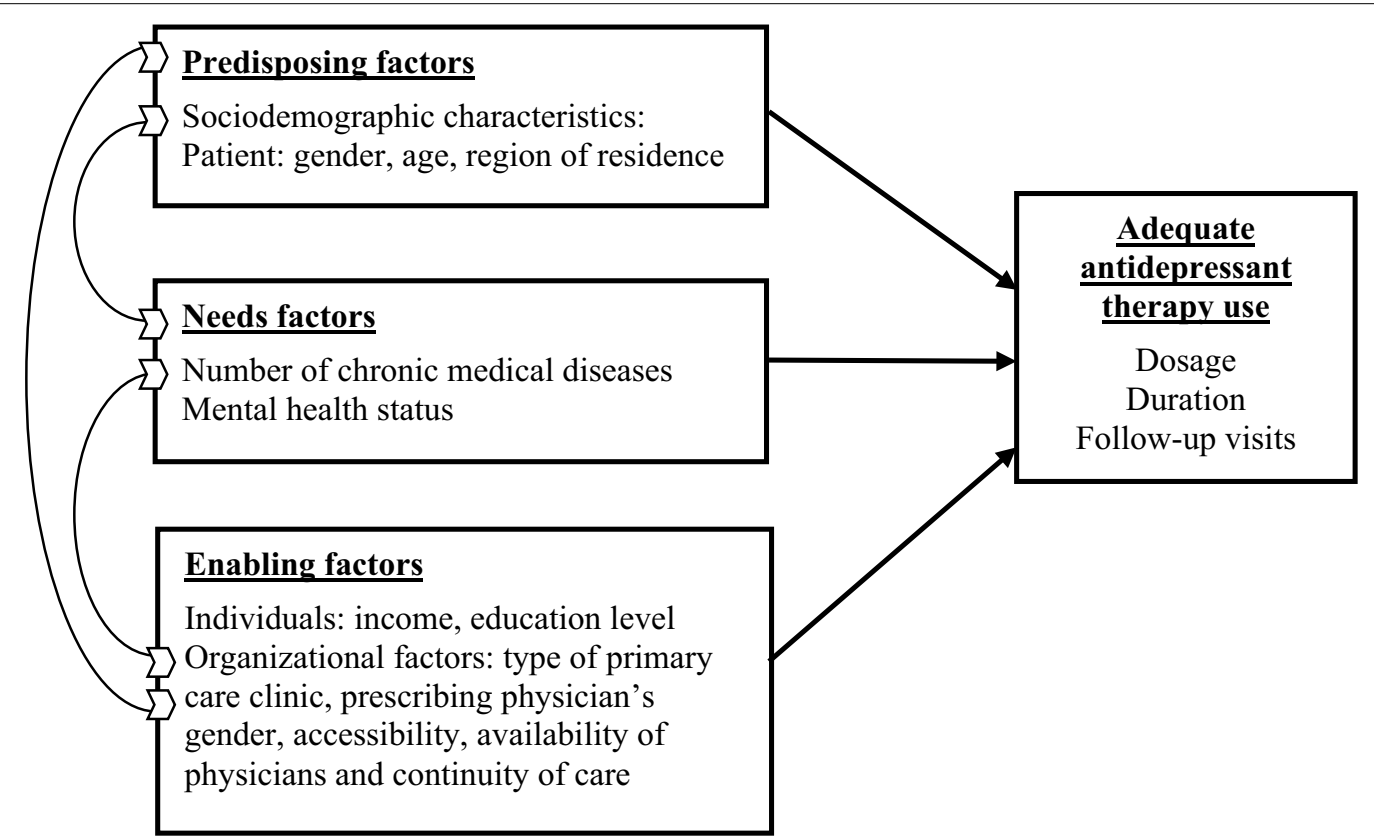

Fig. 1 Adapted Andersen-Newman's model (Adapted from Andersen and Newman [16]) 


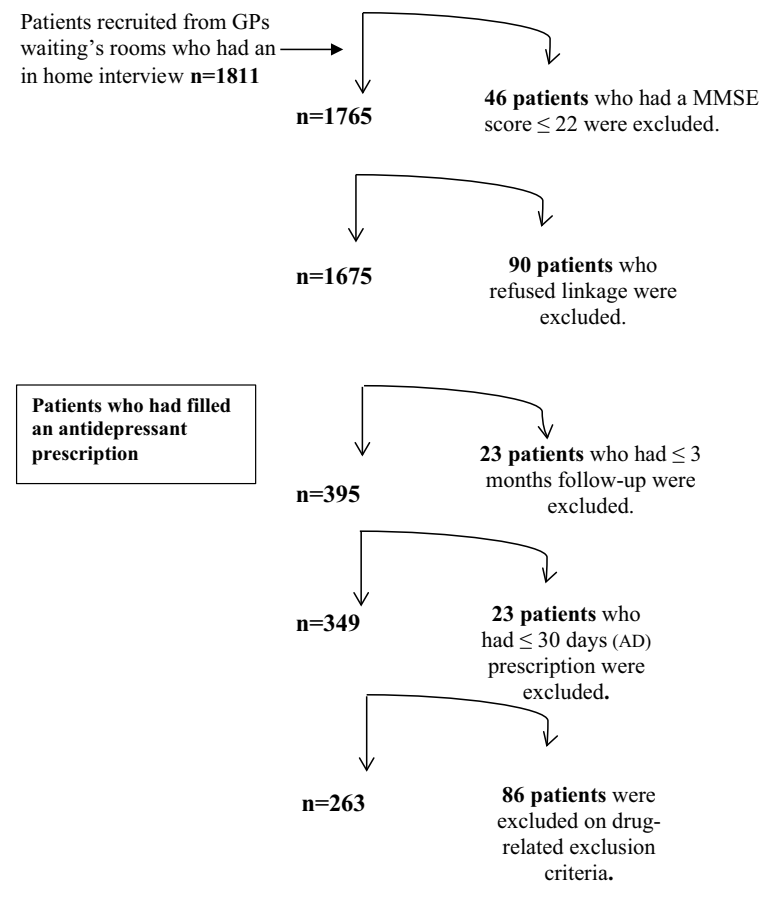

Fig. 2 Flow chart of the study sample

associated with the prescription delivered. In Québec, over $90 \%$ of residents aged $\geq 65$ years are also covered under the public drug insurance plan of the RAMQ.

\section{Measures \\ Independent variables \\ Antidepressants}

The antidepressant drugs present in the RAMQ files included: serotonin re-uptake inhibitors (doxepin $\mathrm{n}=2$, fluoxetine $\mathrm{n}=3$, duloxetine $\mathrm{n}=3$, fluvoxamine $\mathrm{n}=6$, sertraline $n=11$, paroxetine $n=33$, citalopram $n=101$ ); tricyclic antidepressants (desipramine $\mathrm{n}=1$, trimipramine $\mathrm{n}=1$ and clomipramine $\mathrm{n}=1$; nortriptyline $\mathrm{n}=2$, imipramine $\mathrm{n}=2$, amitriptyline $\mathrm{n}=75$ ) and others antidepressants (moclobemide $\mathrm{n}=1$, $\mathrm{L}$-tryptophan $\mathrm{n}=1$, bupropion $\mathrm{n}=16$, mirtazapine $\mathrm{n}=17$; trazodone $\mathrm{n}=29$; venlafaxine $n=45$ ).

Individuals using only amitriptyline, trazodone, doxepin, clomipramine, duloxetine, imipramine, L-tryptophan and trimipramine were omitted from the analysis. Tricyclic antidepressant such as amitriptyline, doxepin, imipramine and trimipramine should be avoided in the elderly because of their anticholinergic and cardiovascular side effects $[15,20,21,25]$. Trazodone is a strong sedative and has been associated with safety concerns in older adults including orthostatic hypotension and falls (25). Among the 75 patients who received amitriptyline in monotherapy, only 7 patients (9\%) were prescribed a dose of $75 \mathrm{mg}$ and more per day. Amitriptyline is often prescribed at lower doses ( $\leq 75 \mathrm{mg}$ /day) for chronic pain. Further trazodone is frequently prescribed for insomnia at lower doses such as $\leq 100 \mathrm{mg} /$ day, compared to doses over $150 \mathrm{mg} /$ day to treat depression in older adults [22]. Only 2 patients (7\%) received a dose of more than (150 mg/day).

\section{Adequate dose}

For older adults, the CCSMH guidelines recommend starting an antidepressant drug at half the initial adult dose cited in the Canadian Compendium Pharmaceuticals and Specialties (CPS) and aiming for an average dose within one month as tolerated and up to the usual adult recommended maximum dose (see Table 1).

Adequacy of dose was measured using the ratio between the prescribed daily dose (PDD) and the defined daily dose (DDD). The PDD is the average dose prescribed across the number of prescriptions during a treatment episode. The DDD index represents the usual daily adult maintenance dose [23] and has been previously used to assess antidepressant prescription patterns in older adult populations [24, 25]. The ratio PDD/DDD was categorized as follows: (1) adequate if the average recommended dose was met $(\mathrm{PDD} / \mathrm{DDD}=1)$ at 90 days following antidepressant initiation; (2) below recommendation $(\leq 1)$ and above recommendation $(\geq 1)$ if the average recommended dose was not met. When more than one antidepressant was used by the respondent, each antidepressant PDD/DDD ratio was calculated.

\section{Adequate duration}

Adequate duration of antidepressant therapy was based on the CCSMH guidelines that recommend a 12-month minimum duration of antidepressant therapy from the time of remission up to 24 months. Based on the literature and CCSMH recommendations, 455 days (15 months) was retained as the cut-off for adequate maintenance duration. According to Klysner et al. adequate duration is calculated as follows: 90 days for the acute phase and 365 days for the maintenance phase [26]. The duration of an antidepressant episode was measured as a continuous variable representing the number of days where an antidepressant was prescribed as reported in the RAMQ pharmaceutical file.

\section{Adequate antidepressant monitoring}

According to the literature, adequate follow-up visits have been defined as a minimum number of 3 visits with a physician during the first 3 months of initiating antidepressant therapy [27]. The number of follow-up visits were categorized as follows: (1) $0-2$ visits, (2) $\geq 3$ visits with the prescriber of antidepressant medications. 
Table 1 Antidepressants drugs commonly prescribed to older adults, the Anatomical Therapeutical Chemical (ATC) codes, defined daily doses (DDDs), initial, average, maximum recommended and average adequate dose

\begin{tabular}{|c|c|c|c|c|c|c|c|}
\hline \multirow[t]{2}{*}{ ATC } & \multirow[t]{2}{*}{ DDD } & \multicolumn{2}{|c|}{ Antidepressant names } & \multicolumn{4}{|c|}{ Antidepressant (dose Mg/Day) } \\
\hline & & Generic & Trade & $\begin{array}{l}\text { Initial dose } \\
(\mathrm{mg})\end{array}$ & Average dose & $\begin{array}{l}\text { Maximum recommended } \\
\text { dose }\end{array}$ & Average adequate dose (mg) \\
\hline \multicolumn{8}{|c|}{ Selective serotonin re-uptake inhibitors (SSRIs) } \\
\hline N06AB03 & $1 \mathrm{mg}$ & Fluoxetine & Prozac & 5 & $10-20 \mathrm{mg}$ & $20 \mathrm{mg}$ & $10-20$ \\
\hline N06AB04 & $1 \mathrm{mg}$ & Citalopram & Celexa & 10 & $10-20 \mathrm{mg}$ & $20 \mathrm{mg}$ & $10-20$ \\
\hline N06AB05 & $1 \mathrm{mg}$ & Paroxetine & Paxil & $5-10$ & $20 \mathrm{mg}$ & $50 \mathrm{mg}$ & $20-50$ \\
\hline N06AB06 & $1 \mathrm{mg}$ & Sertraline & Zoloft & 25 & $50-150 \mathrm{mg}$ & $200 \mathrm{mg}$ & $50-200$ \\
\hline N06AB08 & $1 \mathrm{mg}$ & Fluvoxamine & Luvox & $25-50$ & $100-200 \mathrm{mg}$ & $300 \mathrm{mg}$ & $100-300$ \\
\hline N06AB10 & $1 \mathrm{mg}$ & Escitalopram & Cipralex & 10 & $20-40 \mathrm{mg}$ & $40 \mathrm{mg}$ & $20-40$ \\
\hline \multicolumn{8}{|c|}{ Tricyclic antidepressants (TCAs) } \\
\hline N06AA01 & $0.1 \mathrm{~g}$ & Desipramine & Norpramin & $10-25$ & $50-150 \mathrm{mg}$ & $300 \mathrm{mg}$ & $50-300$ \\
\hline N06AA & $1 \mathrm{mg}$ & Nortriptyline & Aventyl & $10-25$ & 40-100 mg & $200 \mathrm{mg}$ & $40-200$ \\
\hline \multicolumn{8}{|c|}{ Others antidepressants } \\
\hline N06AX11 & $1 \mathrm{mg}$ & Mirtazapine & Remeron & 15 & $30-45$ mg & $45 \mathrm{mg}$ & $30-45$ \\
\hline N06AX12 & $1 \mathrm{mg}$ & Bupropion & Wellbutrin & 100 & $100 \mathrm{mg}$ bid & $150 \mathrm{mg}$ bid & $200-300$ \\
\hline N06AX16 & $0.1 \mathrm{~g}$ & Venlafaxine & Effexor & 37.5 & $75-225 \mathrm{mg}$ & $375 \mathrm{mg}$ & $75-375$ \\
\hline N06AG02 & $0.3 \mathrm{~g}$ & $\begin{array}{l}\text { Moclobe- } \\
\text { mide }\end{array}$ & Manerix & 150 & 150-300 bid & $300 \mathrm{mg}$ bid & $150-600$ \\
\hline
\end{tabular}

\section{Dependent variables of interest according to Anderson and Newman's healthcare seeking behaviour model Predisposing factors}

The predisposing factors considered in this study included: gender; age (65-74 vs. $\geq 75)$; education level (secondary and less vs. secondary and more); and marital status (married, common-law vs. widowed, separated, divorced, single).

\section{Need factors}

The need factors considered included physical health status: number of chronic medical diseases ( $0-3$ vs. $\geq 4)$; and mental health status, which was measured using the 10-item Kessler Psychological Distress Scale [28] and categorized using a cut-off score of 19 , previously validated in older adults for the presence of a probable mood disorder [29].

\section{Enabling factors}

Enabling individual level factors included annual income dichotomized (1) <\$15,000 (2) $\geq \$ 15,000)$, in reference to the levels designated by Statistics Canada as indicating low socioeconomic status [30]; and participant region of residence was categorized according to population density criteria: (1) metropolitan (100,000 inhabitants), (2) urban (1000 inhabitants), or (3) rural (<1000 inhabitants). For the analysis, region of residence was dichotomized as (1) metropolitan/urban, (2) rural.
Enabling healthcare system factors included the type of primary care clinic visited, the prescribing physician's gender, and indicators of continuity of care, accessibility and availability of physicians in the respondents' area of residence. Primary care (PC) settings included PCs with less than 3 GPs; PCs with at least 3 GPs; family medicine group (FMG) and the centre local de services communautaires (CLSC; local community services centres).

Availability indicators included: (1) the number of full time equivalent general practitioners per 100,000 people in the CLSC (local health service centres) area of the respondent and (2) the retention index, which is the percentage of local general fee-for service medical services used by the population in their CLSC territory over the total number of general fee-for-service medical services used by the population regardless the CLSC territory they received these medical services. The retention index is a measure of the capacity of a region to respond to their population demands of general medical services [31].

Accessibility indicators included: the perceived accessibility index comprising two dimensions: (1) the perceived social accessibility; (2) the perceived time-based and economic accessibility [32] and the Usual Provider of Care (UPC) index [33].

The Continuity of care was assessed using the Continuity of Care Depression Anxiety index (CCDA) [34], which is composed of 23 questions covering: (1) the therapeutic relationship, (2) the informational continuity and (3) 
the management continuity. The Continuity of care was assessed in reference to the last physician visit.

\section{Statistical analysis}

Multivariate logistic regression analyses were carried out to study (i) adequate dose; (ii) adequate duration; (iii) adequate follow-up of visits and (iv), meeting all three criteria as a function of predisposing, enabling and need factors. Odds Ratios (ORs) with 95\% Confidence Intervals (95\% CIs) are presented. Data were analysed using SPSS (version 22.0).

\section{Results}

The study sample included 263 participants who had at least one episode of antidepressant use. Sample characteristics are presented in (Table 2). Among them, 74\%

Table 2 Sample descriptive characteristics as a function of criteria met

\begin{tabular}{|c|c|c|c|}
\hline \multirow[t]{2}{*}{ Factors } & \multicolumn{3}{|c|}{ All criteria of $A D s$ treatment adequacy met bivariate logistic regression } \\
\hline & $N=116 / 263(44 \%)$ (yes \%) & $N=147 / 263(56 \%)$ (no \%) & OR (Cl 95\%) \\
\hline \multicolumn{4}{|l|}{ Gender } \\
\hline Male & $57(48 \%)$ & $63(52 \%)$ & $0.60(0.38-0.97)$ \\
\hline Female & $59(41 \%)$ & $84(59 \%)$ & 1 \\
\hline \multicolumn{4}{|l|}{ Age } \\
\hline $65-74$ years old & $77(43 \%)$ & $101(57 \%)$ & $0.89(0.59-1.51)$ \\
\hline$\geq 75$ & $39(46 \%)$ & $46(54 \%)$ & 1 \\
\hline \multicolumn{4}{|l|}{ Marital status } \\
\hline Married/common-law & $77(44 \%)$ & $97(56 \%)$ & $1.02(0.61-1.70)$ \\
\hline Single/divorced/separated/widowed & $39(44 \%)$ & $56(56 \%)$ & 1 \\
\hline \multicolumn{4}{|l|}{ Region } \\
\hline Metropolitan/urban & $42(48 \%)$ & $101(52 \%)$ & $1.25(0.74-2.08)$ \\
\hline Rural & $74(50 \%)$ & $74(50 \%)$ & 1 \\
\hline \multicolumn{4}{|l|}{ Income } \\
\hline$<15,000 \$$ & $11(50 \%)$ & $11(50 \%)$ & $1.36(0.56-3.29)$ \\
\hline$\geq 15,000 \$$ & $81(42 \%)$ & $110(58 \%)$ & 1 \\
\hline \multicolumn{4}{|l|}{ Education } \\
\hline Less than secondary & $80(44 \%)$ & $102(56 \%)$ & $0.96(0.56-1.64)$ \\
\hline Secondary and more & $34(43 \%)$ & $45(57 \%)$ & 1 \\
\hline \multicolumn{4}{|l|}{ Number of chronic disease } \\
\hline $0-3$ & $34(45 \%)$ & $41(55 \%)$ & $0.93(0.55-1.60)$ \\
\hline$\geq 4$ & $82(44 \%)$ & $106(56 \%)$ & 1 \\
\hline \multicolumn{4}{|l|}{ MD gender } \\
\hline Female & $31(46 \%)$ & $36(54 \%)$ & $1.13(0.64-1.96)$ \\
\hline Male & $85(43 \%)$ & $111(57 \%)$ & 1 \\
\hline \multicolumn{4}{|l|}{ Primary care clinic types } \\
\hline$<3$ physicians & $30(45 \%)$ & $37(55 \%)$ & $0.90(0.49-1.66)$ \\
\hline$\geq 3$ physicians & $37(45 \%)$ & $45(55 \%)$ & $0.89(0.50-1.58)$ \\
\hline CLSC & $3(60 \%)$ & $2(40 \%)$ & $0.49(0.80-3.03)$ \\
\hline FMG & $46(42 \%)$ & $63(58 \%)$ & 1 \\
\hline \multicolumn{4}{|l|}{ Kessler-10 scale } \\
\hline$<19$ & $93(50 \%)$ & $93(50 \%)$ & $1.12(0.67-1.88)$ \\
\hline$\geq 20$ & $68(58 \%)$ & $50(42 \%)$ & 1 \\
\hline Heath system factors & Mean (Cl 95\%) & Mean (Cl 95\%) & OR (Cl 95\%) \\
\hline Number of full time eq. GPs & $58(52-64)$ & $57(53-60)$ & $0.99(0.99-1.01)$ \\
\hline Retention index & $0.72(0.68-0.75)$ & $0.69(0.67-0.72)$ & $0.84(0.23-3.09)$ \\
\hline Accessibility index & $4(3.62-4.83)$ & $4(3.62-4.30)$ & $1.01(0.92-1.09)$ \\
\hline Usual Provider of Care index (0-100) & $89(85.70-92.83)$ & $88(85.41-87.95)$ & $1.01(0.99-1.03)$ \\
\hline Continuity of Care Depression Anxiety index (0-10) & $8(7.8-8.3)$ & $8(7.9-8.2)$ & $0.97(0.91-1.20)$ \\
\hline
\end{tabular}


received one type of antidepressant prescription while $21 \%$ and $5 \%$ received two and three different antidepressants. The prescriptions mainly comprised of serotonin re-uptake inhibitors (45\%), followed by other antidepressants (33\%) and tricyclic antidepressants (22\%). In our sample, the most prescribed antidepressants, with a minimum length of 90 days, were citalopram (29\%), venlafaxine (13\%) and paroxetine (9\%).

The proportion of antidepressant users meeting the criteria for an adequate dose was 66\%; (95\% CI 60-71\%); while $26 \%$ (95\% CI $21-31 \%)$ and $8 \%$ (95\% CI 5-12\%) had a higher and lower antidepressant dose at 90 days after initiation. The average length of antidepressant therapy was 684 days (CI 95\% 633-735) with $60 \%(n=209 / 263)$ meeting the criteria for adequate duration of 455 days. With regards to the number of follow-up visits with the prescriber, $74 \%(n=175 / 236)$ met the criteria of a minimum of 3 visits in the 3 months post initiation. Overall, $44 \%(n=116 / 263)$ of the sample received an adequate antidepressant therapy according to all three criteria, while $36 \%(n=95 / 263), 15 \%(n=40 / 263)$ and $5 \%(12 / 263)$ filled two, one and none of the criteria, respectively.

The multivariate analyses (Table 3) did not show any significant association between the predisposing, enabling and need factors studied and the receipt of adequate antidepressant therapy meeting all three criteria. The results however did show that males $(0.45$ Odds Ratio (OR); CI 95\% 0.23-0.88) and individuals living in a metropolitan/urban region were less likely to receive an adequate antidepressant dose $(0.11$ OR; CI 95\% 0.140.81 ) compared to those living in a rural region. The results also showed that patients with psychological distress $(\mathrm{K}-10 \geq 20)$ were more likely to have an adequate number of follow-up visits (0.45 OR; CI 95\% 0.23-0.89) compared to patients scoring with lower psychological distress.

\section{Discussion}

This study reports on the prevalence and determinants of receiving an adequate antidepressant therapy in a sample of older adults seeking medical services in primary care. The results are based on linked administrative and survey information increasing the validity of results by decreasing the potential for recall bias and the study of a number of important individual socio-demographic factors as well as self-reported physical and mental health status. Our findings showed that the prevalence of older adults who received an adequate antidepressant therapy according to all three-adequacy indicators reached $44 \%$. We are

Table 3 Factors associated with receipt of adequate antidepressant treatment among older adults consulting in general medical settings

\begin{tabular}{|c|c|c|c|c|c|c|c|c|}
\hline & \multicolumn{2}{|c|}{ Dose adequacy } & \multicolumn{2}{|c|}{ Duration adequacy } & \multicolumn{2}{|c|}{ F/UP visit adequacy } & \multicolumn{2}{|c|}{$\begin{array}{l}\text { All criteria } \\
\text { of ads treatment } \\
\text { adequacy }\end{array}$} \\
\hline & AOR & C 195\% & AOR & $\mathrm{Cl} 95 \%$ & AOR & $\mathrm{Cl} 95 \%$ & AOR & $\mathrm{Cl} 95 \%$ \\
\hline Gender: Male vs. female & 0.45 & $(0.23-0.88)$ & 1.43 & $(0.80-2.58)$ & 1.23 & $(0.64-2.38)$ & 1.34 & $(0.69-2.65)$ \\
\hline Age: $65-74$ years vs. $\geq 75$ years & 0.81 & $(0.40-1.65)$ & 1.13 & $(0.63-2.04)$ & 1.03 & $(0.51-2.06)$ & 0.56 & $(0.58-2.21)$ \\
\hline Education: less than Secondary vs. $\geq$ secondary and more & 0.48 & $(0.20-1.15)$ & 0.82 & $(0.43-1.59)$ & 1.21 & $(0.58-2.51)$ & $1 . .22$ & $(0.95-2.46)$ \\
\hline Region of residence: metropolitan/urban vs. rural & 0.11 & $(0.14-0.81)$ & 0.78 & $(0.25-2.48)$ & 0.97 & $(0.25-3.73)$ & 0.85 & $(0.22-3.19)$ \\
\hline Income: $<15,000 \$$ vs. $\geq 10,000 \$$ & 1.43 & $(0.43-4.74)$ & 1.49 & $(0.56-3.98)$ & 2.02 & $(0.64-6.38)$ & 1.14 & $(0.39-3.37)$ \\
\hline Marital status: Married/c-law vs. single/div/sep//widowed & 0.85 & $(0.40-1.80)$ & 0.85 & $(0.45-1.57)$ & 1.43 & $(0.71-2.87)$ & 0.89 & $(0.45-1.17)$ \\
\hline Number of chronic illness: $0-3$ vs. $\geq 4$ & 1.56 & $(0.69-3.50)$ & 0.83 & $(0.43-1.61)$ & 0.91 & $(0.43-1.93)$ & 0.96 & $(0.44-2.08)$ \\
\hline Kessler-10 scale: $<19$ vs. $\geq 20$ & 0.75 & $(0.38-1.46)$ & 1.12 & $(0.64-1.98)$ & 0.45 & $(0.23-0.89)$ & 0.83 & $(0.43-1.57)$ \\
\hline MD gender: female vs. male & 0.78 & $(0.35-1.74)$ & 1.43 & $(0.72-2.85)$ & 1.32 & $(0.62-2.82)$ & 1.26 & $(0.58-2.73)$ \\
\hline Primary clinic types: $<3$ physicians vs. FMG & 0.52 & $(0.19-1.42)$ & 1.48 & $(0.75-2.91)$ & 0.80 & $(0.38-1.69)$ & 0.96 & $(0.43-2.12)$ \\
\hline Primary clinic types: $\geq 3$ physicians vs. FMG & 0.78 & $(0.27-2.31)$ & 0.86 & $(0.42-1.75)$ & 1.73 & $(0.72-4.17)$ & 1.24 & $(0.54-2.84)$ \\
\hline Primary clinic types: CLSC vs. FMG & 0.55 & $(0.04-7.51)$ & 5.43 & $(0.58-51.08)$ & 0.34 & $(0.6-2.07)$ & 1.12 & $(0.08-15.06)$ \\
\hline Number of full time* equivalent GPs & 1.01 & $(0.99-1.02)$ & 0.97 & $(0.98-1.01)$ & 0.99 & $(0.98-1.01)$ & 1.01 & $(0.57-0.99)$ \\
\hline Retention index & 0.35 & $(0.01-12.20)$ & 1.05 & $(0.56-19.84)$ & 0.26 & $(0.01-14.12)$ & 0.99 & $(0.98-1.01)$ \\
\hline Accessibility index & 0.12 & $(0.00-4.73)$ & 0.84 & $(0.04-19.08)$ & 5.02 & $(0.09-37.83)$ & 1.88 & $(0.54-64.79)$ \\
\hline Usual Provider of Care index & 1.01 & $(0.96-1.03)$ & 0.99 & $(0.98-1.01)$ & 1.01 & $(0.98-1.03)$ & 0.99 & $(0.97-1.01)$ \\
\hline Continuity of Care Depression and Anxiety index & 1.11 & $(0.8-1.43)$ & 1.05 & $(0.84-1.31)$ & 0.83 & $(0.64-1.09)$ & 0.97 & $(0.75-1.25)$ \\
\hline
\end{tabular}

$A O R$ adjusted odd ratio

* Number of full time equivalent general practitioners per 100,000 people in the CLSC (local health service centers) area of the respondent 
not aware of studies that have considered dosage, duration and follow-up visits in defining adequacy of antidepressant therapy in older adults. In a previous study, Robinson et al. reported in a mixed-age group sample that $19 \%$ had received antidepressant therapy according to the number of follow-up visits and length of therapy during the acute and continuation phases [35]. Others, using fewer criteria in adults, have also reported similar results in the proportion of respondents receiving adequate antidepressant prescription $[2,36]$. Consistent with previous findings $[20,37]$ no association was observed between overall adequate antidepressant therapy and individual and healthcare system characteristics studied.

These findings could in part be explained by the fact that our sample is covered under a publicly funded healthcare system, and therefore individual socio-demographic and health system characteristics would not influence the adequacy of therapy. Second, several studies have suggested that adequacy of antidepressant therapy is associated with perceived stigma, effectiveness, worries about medication dependence and side effects and treatment preferences $[4,38]$. In a mixed-age population of primary care patients, Prins et al. showed that receipt of an adequate antidepressant therapy was associated with patient's perceived need for medication [10].

Our study also showed that $66 \%$ of antidepressant users received an adequate dose; while $26 \%$ were prescribed a lower dose, which is similar to previous studies in older adult patients $[1,4,39]$. Although, older adults should start with low antidepressant doses to minimize side effects, the goal is to reach a therapeutic dose [15]. Nevertheless, a Canadian study exploring physician intentions on maintenance therapy and maximum antidepressant doses showed a significant preference for lower antidepressant doses than those recommended in older adult patients [40]. Possible important factors associated with low antidepressant prescribed doses in older adults may include the impact of adverse secondary effects which can be explored in future studies [38].

With respect to duration, our findings showed that $51 \%$ of users were prescribed an antidepressant for more than 12 months. Very few primary care studies have examined antidepressant maintenance treatment in older adult populations [41]. In Fitch et al. study, 65\% of family physicians reported that they discontinue antidepressant medication after nine months [40]. A recent study examining incident antidepressant users found that close to $45 \%$ of older adults had at least eight months of therapy [42]. Hunot et al. in a primary care setting, also reported that antidepressant adherence was associated with patient willingness to receive pharmacotherapy versus psychotherapy [43].
Our results also showed that the majority of users received an adequate number of follow-up visits. The literature has shown estimates ranging between 35 and $62 \%$ in mixed-age samples of adults outpatients $[13,14,44]$.

\section{Limitations}

This study has some limitations. Although, the majority of antidepressant medications are prescribed for depression in general practices, we could not ascertain from our data that all antidepressant users in our sample have an indication for depression $[1,45]$. However, a new study showed that depression is the main indication for antidepressant prescriptions in Québec [46]. Moreover, participants using antidepressants not indicated for depression in older adults such as amitriptyline, doxepin clomipramine, duloxetine, imipramine, L-tryptophan and trimipramine, which could have been given for other reasons; as well as lower doses of trazodone, usually prescribed for insomnia, were removed from the analyses to increase caseness for depression.

Further, antidepressant use could be for health problems other than common mental disorders such as anxiety, which usually requires lower doses and shorter duration of treatment, leading to a possible misclassification of patients that may have resulted in an underestimation of the prevalence of overall treatment adequacy. Further, the low adequacy rate of antidepressant treatment according to all three-adequacy criteria in our study could be attributed to the fact that clinical practice guideline use is limited and many physicians prescribe medication based on their clinical intuition $[47,48]$. Furthermore, by excluding prescriptions such as amitriptyline and trazodone, we may have excluded patients with depression who had benefited from them in the past and therefore underestimated the prevalence of adequate antidepressant therapy. Further, participants receiving a greater dose than the recommended maximum dose could have indeed received an adequate antidepressant therapy if they were non-responsive to standard recommended doses and the clinician concluded as to no greater risk of toxicity. This may have underestimated respondents with an adequate dose. Regarding the length of the treatment, for some patients, shorter antidepressant duration may be clinically justified because of side effects or referral to private psychiatrist and psychological services causing misclassification of those patients as having received an inadequate length of treatment.

Regarding the number of follow-up visits, it was not possible to ascertain whether the visits to the prescribing physician, were specifically related to the monitoring of the antidepressant treatment, which may have overestimated the results. Nevertheless, we believe that any 
contact with the physician provides an opportunity for monitoring. Furthermore, the cut-off of three minimum follow-up visits after an antidepressant therapy initiation had been validated in previous studies [35, 44]. Finally, the study sample was limited to older antidepressant users consulting in primary care setting in one region of Québec. This region however is representative of the province of Québec. The results may be generalizable to other countries with a public drug insurance plan and universal health system.

An important strength of this study was that it included newer antidepressants commonly used to treat depression. Therefore, our study may have better highlighted the reality of antidepressant prescription in primary care settings. Our study is also one of first primary care study to use three important variables for defining adequacy of antidepressant therapy in Canadian older adults.

\section{Conclusion}

Our results lead us to conclude that antidepressant treatment adequacy still falls short of guideline recommendations. Our findings are consistent with existing literature [1-3]. Strategies to promote adequate recommended duration of antidepressant therapy and monitoring follow-up visits in older adults should be encouraged. Studies with large samples of older adult patients, in particular those at high risk for relapse, are still needed to better understand factors associated with the adequacy of antidepressant therapy such as physician prescribing patterns and patient treatment preferences.

\section{Authors' contributions}

VM, the corresponding author contributed to the literature review and carried out the analyses and interpretation of data and the writing of the paper. HMV participated in the study design, the interpretation of the results and the writing of the paper. MP participated in the drafting and the revising of the paper. All authors approved the final manuscript.

\section{Author details}

${ }^{1}$ Clinical Sciences Program, Faculty of Medicine and Health Sciences, Université de Sherbrooke, Sherbrooke, QC, Canada. ${ }^{2}$ Faculty of Medicine and Health Sciences, Université de Sherbrooke, Sherbrooke, QC, Canada. ${ }^{3}$ Research Center, Charles Le Moyne Hospital, Greenfield Park, QC, Canada. ${ }^{4}$ Department of Community Health, University of Sherbrooke, Sherbrooke, QC, Canada.

\section{Acknowledgements}

The author's would like to thank Dr. D. Berbiche for creating dataset and statistical support.

\section{Competing interests}

The authors declare that they have no competing interests.

\section{Availability of data}

The datasets supporting the conclusion of this article are available from the corresponding author on reasonable request.

\section{Consent for publication}

Participants provided written informed consent to publish data from their interviews.

\section{Ethics approval and consent to participate}

The study was approved by the ethics committee of the University of Sherbrooke's Institute of Geriatrics All participants provided a signed informed consent.

\section{Funding}

The ESA-Services study was funded by the Québec Health Research Fund (Fonds de Recherche du Québec-Santé (FRQ-S) (Operating Grant \# 16000). HMV is supported by an FRQ-S Senior research salary award.

\section{Publisher's Note}

Springer Nature remains neutral with regard to jurisdictional claims in published maps and institutional affiliations.

Received: 20 October 2016 Accepted: 29 July 2017

Published online: 22 August 2017

\section{References}

1. Wang PS, Schneeweiss S, Brookhart MA, Glynn RJ, Mogun H, Patrick AR, Avorn J. Suboptimal antidepressant use in the elderly. J Clin Psychopharmacol. 2005;25(2):118-26.

2. Unützer J, Simon G, Belin TR, Datt M, Katon W, Patrick D. Care for depression in $\mathrm{HMO}$ patients aged 65 and older. J Am Geriatr Soc. 2000;48(8):871-8.

3. Wilkinson P, Izmeth Z. Continuation and maintenance treatments for depression in older people. Cochrane Database Syst Rev. 2012;11:CD006727. doi:10.1002/14651858.CD006727.pub2.

4. Unützer J, Katon W, Callahan CM, Williams JW Jr, Hunkeler E, Harpole L, et al. Depression treatment in a sample of 1,801 depressed older adults in primary care. J Am Geriatr Soc. 2003;51(4):505-14.

5. Hepner KA, Rowe M, Rost K, Hickey SC, Sherbourne CD, Ford ED, et al. The Effect of adherence to practice guidelines on depression outcomes. Intern Med. 2007;147(3):320-9.

6. Andrews G, Issakidis C, Sanderson K, Corry J, Lapsley H. Utilising survey data to inform public policy: comparison of the cost-effectiveness of treatment of ten mental disorders. Br J Psychiatry. 2004;184(6):526-33.

7. Menchetti M, Casini F, Versari M, Bortolotti B, Nespeca C, Berardi D. Pharmacological treatment of depression in primary care. An updated literature review (2000-2009). Clin Neuropsychiatry. 2011;8(4):234-42.

8. Sewitch MJ, Blais R, Rahme E, Galarneau S, Bexton B. Response to a diagnosis of late-life depression: a population study in Quebec pharmacologic. Can J Psychiatry. 2006;51(6):363-70.

9. Charbonneau A, Rosen AK, Ash AS, Owen RR, Kader B, Spiro A III, et al. Measuring the quality of depression care in a large integrated health system. Med Care. 2003;41(5):669-80.

10. Prins MA, Verhaak PF, Smolders M, Laurant MG, van der Meer K, Spreeuwenberg $P$, et al. Patient factors associated with guideline-concordant treatment of anxiety and depression in primary care. J Gen Intern Med. 2010;25(7):648-55.

11. Harman JS, Edlund MJ, Fortney JC. Disparities in the adequacy of depression treatment in the United States. Psychiatr Serv. 2004;55(12):1379-85.

12. Wells KB, Schoenbaum M, Unützer J, Lagomasino IT, Rubenstein LV. Quality of care for primary care patients with depression in managed care. Arch Fam Med. 1999;8(6):529-36.

13. Duhoux A, Fournier L, Gauvin L, Roberge P. Quality of care for major depression and its determinants: a multilevel analysis. BMC Psychiatr. 2012;17(12):142.

14. Wang PS, Berglund P, Kessler RC. Recent care of common mental disorders in the United States: prevalence and conformance with evidencebased recommendations. J Gen Intern Med. 2000;15(5):284-92.

15. Canadian coalition for senior's mental health. In: National guidelines for seniors' mental health 2006. The assessment and treatment of depression. http://www.CCSMPA.ca/en/guidelinesUsers.cfmH. Accessed 15 Oct 2014

16. Andersen R, Newman JF. Societal and individual determinants of medical care utilization in the United States. Milbank Mem Fund Q Health Soc. 1973;51(1):95-124. 
17. Préville M, Mechakra-Tahiri SD, Vasiliadis HM, Mathieu V, Quesnel L, Gontijo-Guerra S, et al. Family violence among older adult patients consulting in primary care clinics: results from the ESA (Enquête sur la santé des aînés) services study on mental health and aging. Can J Psychiatry. 2014;59(8):426-33.

18. Préville M, Lamoureux-Lamarche C, Vasiliadis HM, Grenier S, Potvin O, Quesnel $L$, et al. The 6-month prevalence of posttraumatic stress syndrome (PTSS) among older adults: validity and reliability of the PTSS scale. Can J Psychiatry. 2014;59(10):548-55.

19. Folstein MF, Folstein SE, McHugh PR. "Mini-mental state". A practical method for grading the cognitive state of patients for the clinician. J Psychiatr Res. 1975;12(3):189-98.

20. Burton C, Anderson N, Wilde K, Simpson CR. Factors associated with duration of new antidepressant treatment: analysis of a large primary care database. Br J Gen Pract. 2012;62(595):104-12.

21. Campanelli CM. American geriatrics society updated beers criteria for potentially inappropriate medication use in older adults: the American geriatrics society 2012 beers criteria update expert panel. J Am Geriatr Soc. 2012;60(4):616-31.

22. Mc Call WV. Sleep in the elderly: burden, diagnosis, and treatment. Prim Care Companion J Clin Psychiatry. 2004;6(1):9-20.

23. WHO: Collaborating centre for drug statistics methodology. http://www. whocc.no/ddd. Accessed 20 Jun 2014.

24. Préville $M$, Vasiliadis H-M, Bossé $C$, Dionne PA, Voyer P, Brassard J. Pattern of psychotropic drug use among older adults having a depression or an anxiety disorder: results from the longitudinal ESA study. Can J Psychiatry. 2011;56(6):348-57.

25. Coupland C, Dhiman P, Morriss R, Arthur A, Barton G, Hippisley-Cox J. Antidepressant use and risk of adverse outcomes in older people: population based cohort study. BMJ. 2011;2:343.

26. Klysner R, Bent-Hansen J, Hansen HL, Lunde RM, Pleidrup E, Poulsen DL. Efficacy of citalopram in the prevention of recurrent depression in elderly patients: placebo-controlled study of maintenance therapy. Br J Psychiatry. 2002;181(7):29-35.

27. Horgan CM, Merrick EL, Stewart MT, Scholle SH, Shih S. Improving Medication management of depression in health plans. Psychiatr Serv. 2008;59(1):72-7.

28. Kessler RC, Barker PR, Colpe LJ, Epstein JF, Gfroever JC, Hipiri E, et al. Screening for serious mental illness in the general population. Arch Gen Psychiatry. 2003;60(2):184-9.

29. Vasiliadis HM, Chudzinski V, Gontijo-Guerra S, Préville M. Screening instruments for a population of older adults: the 10-item Kessler Psychological Distress Scale (K10) and the 7-item Generalized Anxiety Disorder Scale (GAD-7). Psychiatry Res. 2015:228(1):89-94.

30. Statistics Canada. Supplement to health reports, vol. 13, http://www. statcan.gc.ca/pub/82-003-s/2002001/pdf/4195132-eng.pdf. Accessed 11 Jun 2014.

31. Mireault J, Lemay A. Analyses cliniques des hospitalisations de la population de ville de Laval et des patients de la Cité de la Santé de Laval, Montréal. Association des hôpitaux du Québec. 1999;113.

32. Dever GEA, Champagne F. Epidemiology in health services management. Rockville: Aspen Publication; 1984
33. Breslau N, Reeb KG. Continuity of care in a university-based practice. J Med Educ. 1975;50(10):965-9.

34. Sytema S, Burgess P. Continuity of care and readmission in two service systems: a comparative Victorian and Groningen case-register study. Acta Psychiatr Scand. 1999;100(3):212-9. doi:10.1111/j.1600-0447.1999. tb10848.x.

35. Robinson RL, Long SR, Chang S, Able S, Baser O, Obechain RL, et al. Highe costs and therapeutic factors associated with adherence to NCQA HEDIS antidepressants medication management measures: analysis of administrative claims. J Manag Care Pharm. 2006;12(1):43-54.

36. Harman JS, Edlund MJ, Fortney JC, Kallas H. The influence of comorbid chronic medical conditions on the adequacy of depression care for older Americans. J Am Geriatr Soc. 2005;53(12):2178-83.

37. Weich S, Nazareth I, Morgan L, King M. Treatment of depression in primary care. Socio-economic status, clinical need and receipt of treatment. Br J Psychiatry. 2007;191(8):164-9.

38. Ivanova Jl, Bienfait-Beuzon C, Birnbaum HG, Connolly C, Emani S, Sheehy M. Physicians' decisions to prescribe antidepressant therapy in older patients with depression in a US managed care plan. Drugs Aging. 2011:28(1):51-62

39. Mottram P, Wilson K, Strobl J. Antidepressants for depressed elderly. Cochrane Database Syst Rev. 2006:(1):CD003491.

40. Fitch K, Molnar FJ, Power B, Wilkins D, Man-Son-Hing D. Antidepressants use in older people: family physicians' knowledge, attitudes, and practices. Can Fam Phys. 2005;51(1):80-1

41. Freudenstein $U$, Jagger C, Arthur A, Donner-Banzhoff N. Treatments for late life depression in primary care-a systematic review. Fam Pract. 2001;18(3):321-7.

42. Conseil du médicament. Portrait de l'usage des antidépresseurs chez les adultes assurés par le régime public d'assurance médicaments du Québec. 2011. http://www.inesss.qc.ca/fileadmin/doc/CDM/Etudes/ CdM-Portraitantidepresseurs-201101.pdf. Accessed 13 May 2014.

43. Hunot VM, Horne R, Leese MN, Churchill RC. A cohort study of adherence to antidepressants in primary care: the influence of antidepressant concerns and treatment preferences. Prim Care Companion J Clin Psychiatry. 2007;9(2):91-9.

44. Pinto-Meza A, Fernandez A, Serrano-Blanco A, Haro JM. Adequacy of antidepressant treatment in Spanish primary care: a naturalistic six-month follow-up study. Psychiatr Serv. 2008;59(1):78-83.

45. Gardarsdottir H, Heerdink ER, van Dijk L, Egberts AC. Indications for AD drug prescribing in general practice in the Netherlands. J Affect Disord. 2007:98(1-2):109-15.

46. Wong J, Motulsky A, Eguale T, Buckeridge DL, Abrahamowicz M, Tamblyn R. Treatment indications for antidepressants prescribed in primary care in Quebec, Canada, 2006-2015. J Am Med Assoc. 2016;315(20):2230-2. doi:10.1001/jama.2016.3445.

47. Fleury M, Imboua A, Aubé D, Farand L, Lambert Y. General practitioners'management of mental disorders: a rewarding practice with considerable obstacles. BMC Fam Pract. 2012:16:13-9.

48. Mercier A, Auger-Aubin I, Lebeau JP, Van Royen P, Peremans L. Understanding the prescription of antidepressants: a qualitative study among French GPs. BMC Fam Pract. 2011;24(12):99.

\section{Submit your next manuscript to BioMed Central and we will help you at every step:}

- We accept pre-submission inquiries

- Our selector tool helps you to find the most relevant journal

- We provide round the clock customer support

- Convenient online submission

- Thorough peer review

- Inclusion in PubMed and all major indexing services

- Maximum visibility for your research

Submit your manuscript at www.biomedcentral com/submit

C BioMed Central 